\title{
Percutaneous image guided electrochemotherapy of hepatocellular carcinoma: technological advancement
}

\author{
Mihajlo Djokic ${ }^{1}$, Rok Dezman², Maja Cemazar ${ }^{3,4}$, Miha Stabuc ${ }^{2}$, Miha Petric ${ }^{1}$, \\ Lojze M. Smid ${ }^{5}$, Rado Jansa ${ }^{5}$, Bostjan Plesnik ${ }^{1}$, Masa Bosnjak ${ }^{3}$, Ursa Lampreht Tratar ${ }^{3}$, \\ Blaz Trotovsek ${ }^{1}$, Bor Kos $^{6}$, Damijan Miklavcic ${ }^{6}$, Gregor Sersa ${ }^{3,7}$, Peter Popovic ${ }^{2}$ \\ 1 University Medical Centre Ljubljana, Clinical Department of Abdominal Surgery, Ljubljana, Slovenia \\ 2 University Medical Centre Ljubljana, Clinical Institute of Radiology, Ljubljana, Slovenia \\ ${ }^{3}$ Institute of Oncology Ljubljana, Department of Experimental Oncology, Ljubljana, Slovenia \\ ${ }^{4}$ University of Primorska, Faculty of Health Sciences, Izola, Slovenia \\ ${ }^{5}$ University Medical Centre Ljubljana, Clinical Department of Gastroenterology, Ljubljana, Slovenia \\ ${ }^{6}$ University of Ljubljana, Faculty of Electrical Engineering, Ljubljana, Slovenia \\ 7 University of Ljubljana, Faculty of Health Sciences, Ljubljana, Slovenia
}

Radiol Oncol 2020; 54(3): 347-352.

Received 14 Maj 2020

Accepted 1 June 2020

Correspondence to: Prof. Gregor Serša, Ph.D., Institute of Oncology Ljubljana, Department of Experimental Oncology, Zaloška 2, SI-1000 Ljubljana, Slovenia. E-mail: gsersa@onko-i.si and Prof. Peter Popovič, M.D., Ph.D., University Medical Centre Ljubljana, Clinical Institute of Radiology, Zaloška 7, SI-1000 Ljubljana, Slovenia. E-mail: peter.popovic@kclj.si

Mihajlo Djokic and Rok Dezman contributed equally.

Disclosure: Damijan Miklavčič holds patents on electrochemotherapy that have been licensed to IGEA S.p.a (Carpi, Italy) and is also a consultant to various companies with an interest in electroporation-based technologies and treatments. The other authors have no competing interests.

Background. Electrochemotherapy is an effective treatment of colorectal liver metastases and hepatocellular carcinoma (HCC) during open surgery. The minimally invasive percutaneous approach of electrochemotherapy has already been performed but not on HCC. The aim of this study was to demonstrate the feasibility, safety and effectiveness of electrochemotherapy with percutaneous approach on HCC.

Patient and methods. The patient had undergone the transarterial chemoembolization and microwave ablation of multifocal HCC in segments III, V and VI. In follow-up a new lesion was identified in segment III, and recognized by multidisciplinary team to be suitable for minimally invasive percutaneous electrochemotherapy. The treatment was performed with long needle electrodes inserted by the aid of image guidance.

Results. The insertion of electrodes was feasible, and the treatment proved safe and effective, as demonstrated by control magnetic resonance imaging.

Conclusions. Minimally invasive, image guided percutaneous electrochemotherapy is feasible, safe and effective in treatment of HCC.

Key words: electrochemotherapy; hepatocellular carcinoma; percutaneous; minimally invasive; bleomycin

\section{Introduction}

Electrochemotherapy is safe and effective treatment of cutaneous tumors and metastases, its application is described in the published Standard Operating procedures, and clinical indications defined in NICE, and several other national guidelines. ${ }^{1-3}$

Electrochemotherapy in treatment of deepseated tumors, like liver metastases and hepatocellular carcinoma (HCC) proved to be safe and effective. ${ }^{4-6}$ The three published studies were done 


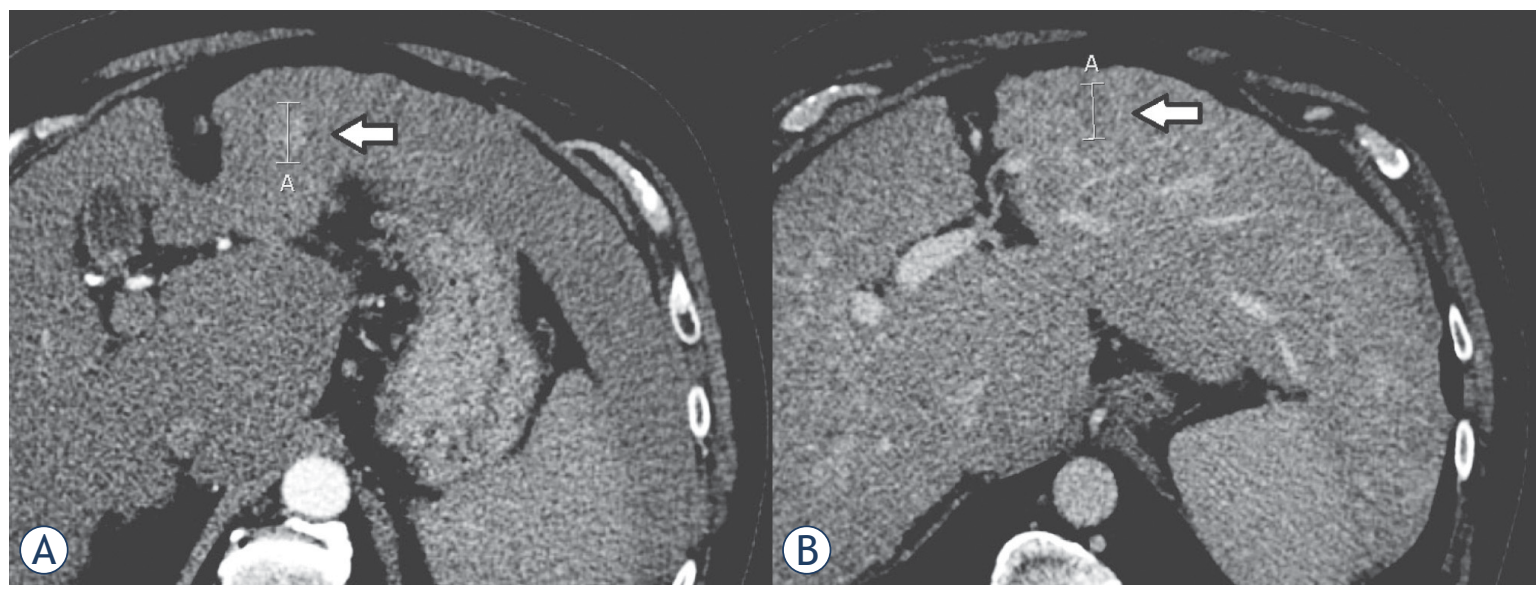

FIGURE 1. A 66-year-old male with hepatocellular carcinoma (HCC). Control CT after drug-eluting bead doxorubicin transarterial chemoembolization (DEBDOX TACE) and microwave ablation (MWA) shows non-target progression in segment III, $18 \mathrm{~mm}$ the largest diameter. (A) Hypervascular lesion in arterial phase. (B) Washout in venous phase.

using electrochemotherapy during open surgery. The surveillance of high-risk population using ultrasound permits to diagnose HCC at an early stage, at which curative treatments can be employed. According to European Association for the Study of Liver (EASL) recommendations, thermal ablation with radiofrequency is the standard of care for patients with Barcelona clinic liver cancer (BCLC) 0 and A, tumors not suitable for surgery. However, in patients with very early stage HCC (BCLC-0) radiofrequency ablation (RFA) in favorable locations can be adopted as first-line therapy even in patients amenable to surgical procedure. Electrochemotherapy is local therapy with similar modes of action as local ablative therapies, e.g. RFA, microwave ablation (MWA) and in particular irreversible electroporation (IRE) ${ }^{7-9}$ However, the main difference between electrochemotherapy and other local ablative therapies is that electrochemotherapy combines two modalities, chemotherapy and the application of electric pulses. Thus, the tumor cells are dying not directly due to the application of physical energy, such as in the case of other local thermal ablative therapies or IRE, but due to the action of chemotherapeutic drug, which in the case of bleomycin means that the cells are dying by mitotic cell death. ${ }^{10}$ Therefore, electrochemotherapy is effective and safe in treatment of tumors located in close proximity to major hepatic vessels ${ }^{11-13}$ and can be performed by image guided percutaneous approach. ${ }^{14}$

Percutaneous approach of electrode insertion is well established in IRE. Several studies demonstrate the feasibility and safety of percutaneous approach of IRE in treatment of liver tumors, in- cluding HCC., ${ }^{9,15-17}$ Some reports describe percutaneous approach also for electrochemotherapy of cholangiocarcinoma, spine metastases ${ }^{18,19}$, lysis of portal vein thrombosis in hepatic hilum, and metastasis from renal cell cancer, however not in treatment of HCC. ${ }^{20-23}$ In this report we therefore tested the feasibility, safety and effectiveness of electrochemotherapy with image guided percutaneous approach, in a patient with HCC.

\section{Patient and methods}

Sixty six-year old male patient was presented at multidisciplinary team meeting with multifocal HCC in segments III, V, VI in September 2017. At the time that patient was presented he had Child A liver cirrhosis - ethylic etiology, arterial hypertension and diabetes type 2. He was a former smoker and had a history of excessive alcohol consumption. In 2018 he had undergone 1a and 1b drugeluting bead doxorubicin transarterial chemoembolization (DEBDOX TACE) treatment of hepatic lesions. Two months after the treatment, control computed tomography (CT) showed complete response of the target lesions in segments III and VI and stable disease of the lesion in segment V. Therefore, his documentation was reviewed on hepatopancreaticobiliary (HPB) multidisciplinary team meeting, which concluded that the patient is a candidate for MWA of the lesion in segment V. On control CT scan 1 month after MWA, lesion in segment $\mathrm{V}$ was completely avital (complete response), but new lesion, $14 \mathrm{~mm}$ in diameter, in segment III was identified. On CT scan 3 months later 
hypervascular lesion in segment III appeared to be larger - $18 \mathrm{~mm}$ in diameter (Figure 1). No signs of extrahepatic disease were found. According to HPB multidisciplinary team meeting, the patient was eligible candidate for percutaneous electrochemotherapy. The patient signed informed consent and was treated in the frame of the clinical study (NCT02291133) approved by the National Ethics Committee (21k/02/14) of the Republic of Slovenia.

Electrochemotherapy was performed according to the standard operating procedures for electrochemotherapy ${ }^{2}$ and as described in previous study on electrochemotherapy of $\mathrm{HCC}^{5}$, performed during the open surgery using cone-beam computed tomography $(\mathrm{CBCT})$ guided percutaneous approach.

\section{Results}

Treatment was performed under general anesthesia and deep muscle relaxation. The patient was positioned in supine position. Because the tumor was not visible on ultrasound and CBCT with a contrast agent, we decided for angiography to visualize the lesion. Coeliac truncus was reached through the punction of common femoral artery and left hepatic artery was selectively catheterized. CBCT (Siemens Medical Solutions, Forchheim, Germany) was performed with the administration of non-ionic contrast agent (Ultravist 370®, Bayer HealthCare) through a power injector (Avanta ${ }^{\circledR}$, Medrad, Bayer HealthCare). CBCT after contrast injection through 2.4 F microcatheter (Progreat ${ }^{\circledR}$, Terumo Europe N.V.) into segmental branches for liver segment III confirm $18 \mathrm{~mm}$ large tumor (Figure 2A). Four electrodes with $3 \mathrm{~cm}$ active length were placed percutaneously around the tumor in the form of pseudo-square under stereotactic CBCT guidance according to European Standard Operating Procedures on Electrochemotherapy (ESOPE) recommendations (Figure 2B,C). ${ }^{2}$ The distance between the electrodes ranged from 18 to $23 \mathrm{~mm}$ (Figure 2B, Figure 3A). Then, bleomycin (Bleomycin medac, Medac, Germany) $30.000 \mathrm{IU}$ in $20 \mathrm{ml}$ of physiological saline; $15000 \mathrm{IU} / \mathrm{m}^{2}$, was administered intravenously in bolus lasting 2 minutes. Two trains of 4 electric pulses (duration 100 $\mu \mathrm{s}$, pulse repetition frequency $1 \mathrm{kHz}$ ) of opposite polarity with voltage-to-distance ratio of $1000 \mathrm{~V} /$ $\mathrm{cm}$ and were delivered between all electrode pairs starting 8 minutes after the bleomycin injection (total number of pulses $=48$ ). The voltages and me-

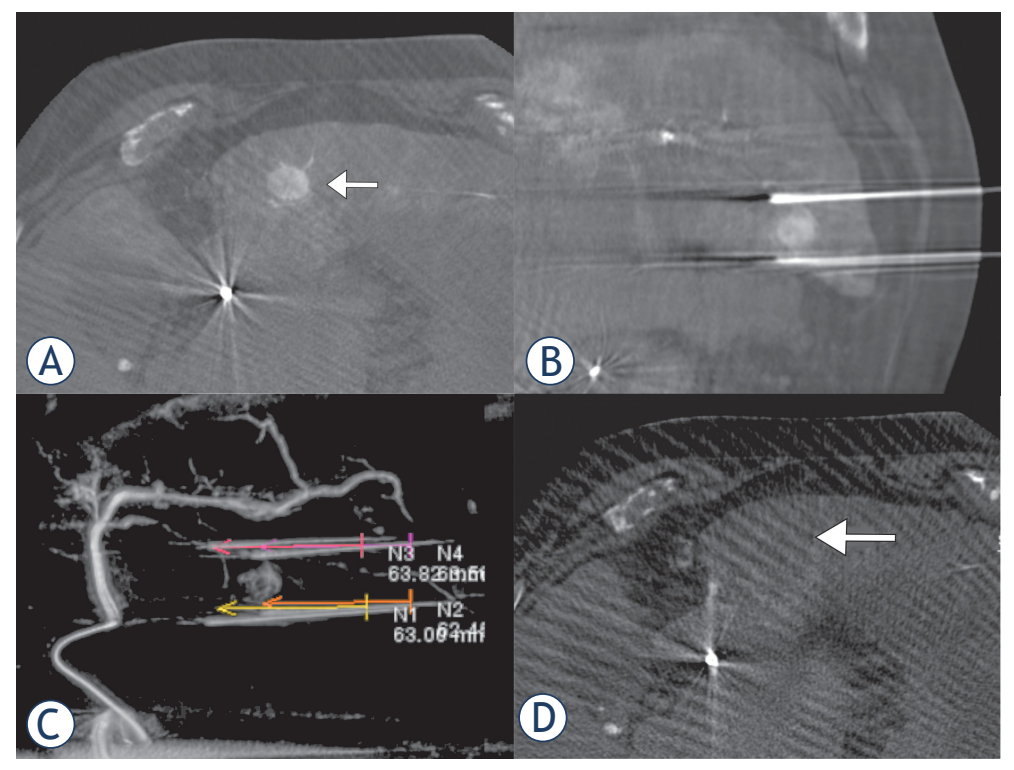

FIGURE 2. A 66- year-old male with hepatocellular carcinoma (HCC). Cone-beam computed tomography (CBCT) demonstrating $\mathrm{HCC}$ before the treatment (A). Position of the electrodes in relation to tumor on СВСТ. (B, C) The absence of the contrast enhancement of the ablated tumor was notable 4 minutes after the electrochemotherapy (D).

TABLE 1. VOLTAGES and currents delivered in the treatment

\begin{tabular}{cccc}
\multicolumn{2}{c}{ Electrode pair } & Voltage [V] & Current [A] \\
\hline 2 & 3 & 2800 & 38.0 \\
4 & 1 & 2800 & 36.5 \\
1 & 3 & 2300 & 34.5 \\
1 & 2 & 2000 & 29.4 \\
3 & 4 & 1800 & 27.7 \\
2 & 4 & 1800 & 26.5 \\
\hline
\end{tabular}

dian currents delivered to each electrode pair are listed in Table 1. Delivery of the electric pulses was synchronized with the ECG, triggered during the refractory phase of the heart. ${ }^{24}$ The maximal current amplitude measured during electroporation of the tumor was $40 \mathrm{~A}$. During the treatment, no changes in cardiologic (ECG, pulse rate) and hemodynamic parameters were noticed. After electrode extraction, control CBCT with contrast injection through microcatheter showed area of avital lesion (Figure 2D). The whole procedure from the induction of anesthesia until the end of the application of electric pulses lasted $1 \mathrm{~h}$ and 10 minutes.

A numeric reconstruction of the performed treatment, prepared using the treatment planning 


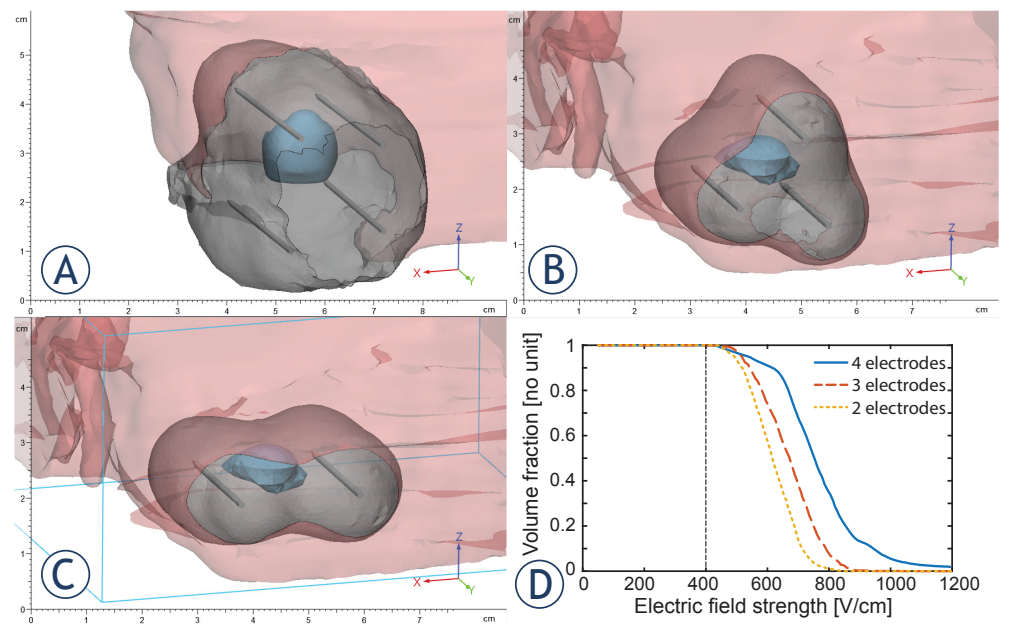

FIGURE 3. Numerical visualization of electric field for successful electrochemotherapy. (A) Reconstruction of actual treatment based on cone-beam computed tomography (CBCT) images. (B) 3 electrode treatment plan based on pre-treatment CECT. (C) 2 electrode treatment plan based on pre-treatment CBCT. (D) Electric field histogram showing the volume fraction of tumor tissue covered by electric fields of at least the strength indicated on the horizontal axis for all three treatments shown in panels A-C.

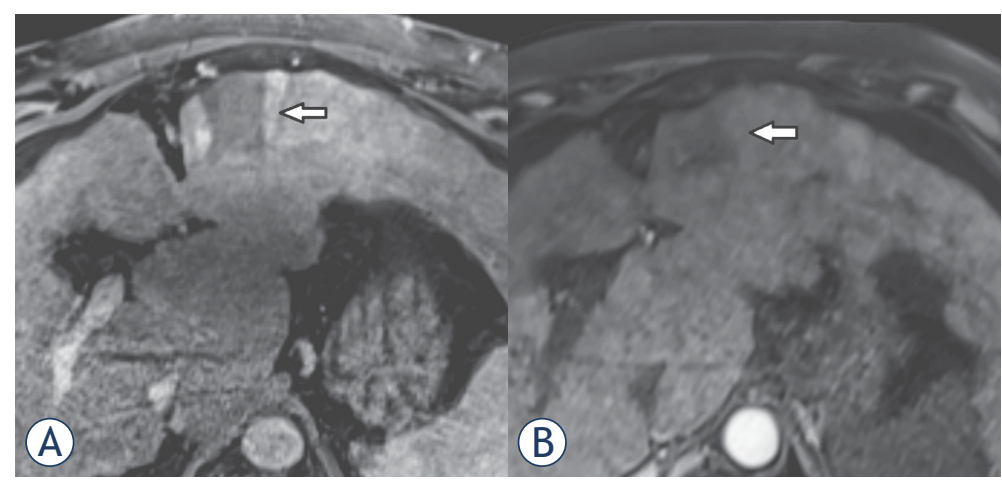

FIGURE 4. A 66-year-old male with hepatocellular carcinoma (HCC). Control MRI of liver 2 months (A) and 6 months (B) after procedure showing an unenhancing area of ablation - a complete response according to mRECIST criteria.

methods presented in previous work showed that whole tumor area with safety margin (range: 6.2 to $39 \mathrm{~mm}$ ) was covered, comprising a total volume of $78 \mathrm{~cm}^{3}$ (Figure $3 \mathrm{~A}$ ). ${ }^{25} \mathrm{~A}$ numerical analysis showed, that a successful treatment would also be possible with a 3 electrode (Figure $3 \mathrm{~B}$ ) and 2 electrode (Figure 3C) configuration. The volumes of obtained lesion are smaller than the actual treatment $\left(26\right.$ and $23 \mathrm{~cm}^{3}$ for the 3 and 2 electrode setup, respectively), but they still achieved a good safety margin (range $3.6 \mathrm{~mm}$ to $21.5 \mathrm{~mm}$ for 2 electrodes and $5.1 \mathrm{~mm}$ to $20.9 \mathrm{~mm}$ for 3 electrodes).

Postprocedural course was uneventful, abdominal ultrasound 24 hours post-electrochemotherapy showed normal postinterventional finding - no bleeding, hematoma or fluid collections. Therefore, patient was discharged the day after the procedure with analgesics and antithrombotic prophylaxis.

Two months after percutaneous electrochemotherapy, control magnetic resonance (MRI) of liver showed $36 \mathrm{~mm}$ large non enhancing area of ablation necrosis within the treated area - complete response of targeted lesion according to modified Response Evaluation Criteria In Solid Tumors (mRECIST) (Figure 4A). The patient was feeling well, in good physical condition and pain-free.

On the second follow-up, 6 months after the procedure control liver MRI showed complete response of the treated lesion with ablated area decreasing in size, which is in line with expected necrosis resolution dynamics and formation of fibrosis. The lesion was in complete response also 18 months after the treatment, however new HCC foci occurred in other locations.

\section{Discussion}

We describe the first case of percutaneous electrochemotherapy of HCC. Minimally invasive, image guide percutaneous electrochemotherapy proved feasible, safe and effective treatment modality, which can be used in selected group of patients with HCC.

The management of HCC has changed in recent years. Percutaneous local ablation is currently considered to be viable treatment for patients with very early $\mathrm{HCC}$, as defined by the BCLC staging system. Indications for percutaneous local ablation include: HCC in BCLC stage A with Child-Pugh class $\mathrm{A} / \mathrm{B}$ cirrhosis; ECOG performance status of $0-1$; ideal tumor size of less than $3 \mathrm{~cm}$ and solitary or multiple lesions (up to three lesions). RFA has been the most widely investigated modality of percutaneous ablation. It has been shown that RFA is a safe method with potential drawback due to the heat sink effect. It is believed that $10-25 \%$ of patients with HCC may not be eligible for RFA due to this effect. ${ }^{26}$

MWA offers all the benefits of RFA as well as some substantial advantages. Promising results of MWA for HCC have been demonstrated in several studies. ${ }^{27-29}$ The advantages of MWA include a larger volume of cellular necrosis, reduction in procedure times, greater temperatures delivered to the target lesion and greater efficacy in lesions in proximity to vascular structures with a reduction in the heat-sink effect compared to RFA. ${ }^{29}$ Due to the higher delivered energy a vessel thrombosis 
as potential complication can occur when tumors adjacent to major vessels are treated. Although extremely rare, these complications have been described. ${ }^{29}$

Electrochemotherapy has already proven effective in treatment of HCC in a series of 17 lesions in 10 patients treated by electrochemotherapy during the open surgery with median tumor size of $24 \mathrm{~mm}$ (range 8-41 mm). No treatment related adverse effects or major post-operative complications were observed. The complete response rate at last follow up ranging from 12 to 31 months was $80 \%$ per patient and $88 \%$ per treated lesion. ${ }^{5}$ This response rate of electrochemotherapy is comparable although lower than the response rate achieved by RFA and MWA. ${ }^{30}$ Newer studies report the response rate in HCC smaller than $30 \mathrm{~mm}$ above $98 \%$ for RFA and MWA with low percentage of local recurrence. ${ }^{31}$

The advantage of the electrochemotherapy is that it is effective in treatment of tumors also located in close proximity of the major hepatic vessels. In comparison to RFA electrochemotherapy is not affected by heat sink effect, and this indication was not proven only in the clinical study treating HCC with electrochemotherapy ${ }^{5}$, but also in the study treating liver metastases of colorectal cancer by IRE. ${ }^{32}$ The safety of treating tumors close to major liver vessels was demonstrated also in the recent study in healthy pigs, where no significant vascular damage/abnormalities were observed in liver vessels, even when the electrodes were inserted through the hepatic or portal vessels. ${ }^{11}$

IRE as an ablation method has also been demonstrated to be effective for treatment of HCC. ${ }^{15,33}$ Similar observations were reported for electrochemotherapy, without major complications. IRE, though, is executed percutaneously in many cancer centers, with the aid of image guidance. ${ }^{34}$ Due to similar technological approach, electrochemotherapy can also be performed percutaneously. Same principles must be followed - careful pre-treatment planning, image guided electrode insertion and safe delivery of electric pulses with ECG synchronization. ${ }^{24,35,36}$ Electrochemotherapy however may offer additional advantages over IRE: shorter treatment duration due to a lower number of pulses required (e.g. 8 vs. 90), the possibility of achieving larger volumes with fewer electrodes and without electrode repositioning.

The advantage of electrochemotherapy in comparison to IRE is its different mode of action. IRE is an ablative technique that by delivering sets of pulses disrupts cell's homeostasis due to cell membrane electroporation leading to cell death.
Therefore, the tumor is ablated in the confined area and no selective action on tumor cells is present. IRE being nonthermal ablative technology also elicits strong local immune response and preserves critical structures which is also well established in electrochemotherapy. Electrochemotherapy however acts through three mechanisms. First one is selective cellular cytotoxicity by drug delivered to cells, and cell death due to mitotic catastrophe. ${ }^{37}$ In that case tumor safety margins can be wider due to predominantly tumor cell death and sparing of normal tissue. Electrochemotherapy, can therefore be employed also in tumors that are bigger than 3 $\mathrm{cm}$ in diameter, which is currently the limit for IRE. The second mode of action is vascular disruption that is well established in electrochemotherapy ${ }^{38}$, but not well explored in IRE. And the third is the elicitation of local immune response ${ }^{39}$ that could be exploited in combination with immunotherapies. ${ }^{40,41}$

Using percutaneous approach will provide electrochemotherapy broader clinical application in treatment of HCC and other liver tumors/metastases, being minimally invasive, with short hospitalization and good patient's compliance.

\section{Acknowledgement}

This work was financially supported by the Slovenian Research Agency (ARRS), grant No. P30003 and P2-0249 and grant of University Clinical Center Ljubljana \#20180061

\section{References}

1. Campana LG, Clover AJ, Valpione S, Quaglino P, Gehl J, Kunte C, et al. Recommendations for improving the quality of reporting clinical electrochemotherapy studies based on qualitative systematic review. Radiol Oncol 2016; 50: 1-13. doi: 10.1515/raon-2016-0006

2. Gehl J, Sersa G, Matthiessen LW, Muir T, Soden D, Occhini A, et al. Updated standard operating procedures for electrochemotherapy of cutaneous tumours and skin metastases. Acta Oncol 2018; 57: 874-82. doi:10.1080/02 84186X.2018.1454602

3. Campana LG, Miklavčič D, Bertino G, Marconato R, Valpione S, Imarisio I, et al. Electrochemotherapy of superficial tumors - current status: basic principles, operating procedures, shared indications, and emerging applications. Semin Oncol 2019; 46: 173-91. doi: 10.1053/j.seminoncol.2019.04.002

4. Edhemovic I, Brecelj E, Gasljevic G, Snoj M, Miklavcic D, Gadzijev E, et al. Intraoperative electrochemotherapy of colorectal liver metastases. I Surg Oncol 2014; 110: 320-7. doi: 10.1002/jso.23625

5. Djokic M, Cemazar M, Popovic P, Kos B, Dezman R, Bosnjak M, et al. Electrochemotherapy as treatment option for hepatocellular carcinoma, a prospective pilot study. Eur J Surg Oncol 2018; 44: 651-7. doi: 10.1016/j. ejso.2018.01.090 
6. Edhemovic I, Brecelj E, Cemazar M, Boc N, Trotovsek B, Djokic M, et al. Intraoperative electrochemotherapy of colorectal liver metastases: a prospective phase II study. Eur J Surg Oncol 2020; Epub ahead of print. doi: 10.1016/j.ejso.2020.04.037

7. Johnson BW, Wright GP. Regional therapies for the treatment of primary and metastatic hepatic tumors: a disease-based review of techniques and critical appraisal of current evidence. Am J Surg 2019; 217: 541-5. doi: 10.1016/j.amjsurg.2018.10.018

8. Lyu C, Lopez-Ichikawa M, Rubinsky B, Chang TT. Normal and fibrotic liver parenchyma respond differently to irreversible electroporation. HPB 2019; 21: 1344-53. doi: 10.1016/j.hpb.2019.01.019

9. Geboers B, Scheffer HJ, Graybill PM, Ruarus AH, Nieuwenhuizen S, Puijk $\mathrm{RS}$, et al. High-voltage electrical pulses in oncology: Irreversible elec troporation, electrochemotherapy, gene electrotransfer, electrofusion, and electroimmunotherapy. Radiology 2020; 295: 254-72. doi: 10.1148/radiol.2020192190

10. Miklavčič D, Mali B, Kos B, Heller R, Serša G. Electrochemotherapy: from the drawing board into medical practice. Biomed Eng Online 2014; 13: 29. doi: $10.1186 / 1475-925 X-13-29$

11. Brloznik M, Boc N, Sersa G, Zmuc J, Gasljevic G, Seliskar A, et al. Radiological findings of porcine liver after electrochemotherapy with bleomycin. Radiol Oncol 2019; 53: 415-26. doi: 10.2478/raon-2019-0049

12. Zmuc J, Gasljevic G, Sersa G, Edhemovic I, Boc N, Seliskar A, et al. Large liver blood vessels and bile ducts are not damaged by electrochemotherapy with beomycin in pigs. Sci Rep 2019; 9: 3649. doi: 10.1038/s41598-019-40395-y.

13. Gasljevic G, Edhemovic I, Cemazar M, Brecelj E, Gadzijev EM, Music MM, et al. Histopathological findings in colorectal liver metastases after electrochemotherapy. PLoS One 2017; 12: e0180709. doi: 10.1371/journal. pone.0180709.

14. Probst U, Fuhrmann I, Beyer L, Wiggermann P. Electrochemotherapy as a new modality in interventional oncology: a review. Technol Cancer Res Treat 2018; 17: 1533033818785329. doi: 10.1177/1533033818785329

15. Sutter O, Calvo J, N'kontchou G, Nault J-C, Ourabia R, Nahon P, et al. Safety and efficacy of irreversible electroporation for the treatment of hepatocellular carcinoma not amenable to thermal ablation techniques. Radiology 2017; 284: 877-86. doi: 10.1148/radiol.2017161413

16. Kalra N, Gupta P, Gorsi U, Bhujade H, Chaluvashetty SB, Duseja A, et al Irreversible electroporation for unresectable hepatocellular carcinoma: initial experience. Cardiovasc Intervent Radiol 2019; 42: 584-90. doi: 10.1007/ s00270-019-02164-2

17. Kalra N. Locoregional treatment for hepatocellular carcinoma: the best is yet to come. World J Radiol 2015; 7: 306-18. doi: 10.4329/wjr.v7.i10.306

18. Gasbarrini A, Campos WK, Campanacci L, Boriani S. Electrochemotherapy to metastatic spinal melanoma: a novel treatment of spinal metastasis? Spine 2015; 40: E1340-6. doi: 10.1097/BRS.0000000000001125

19. Cornelis FH, Ben Ammar M, Nouri-Neuville M, Matton L, Benderra MA Gligorov J, et al. Percutaneous image-guided electrochemotherapy of spine metastases: initial experience. Cardiovasc Intervent Radiol 2019; 42: 1806 9. doi: 10.1007/s00270-019-02316-4

20. Tarantino L, Busto G, Nasto A, Nasto RA, Tarantino P, Fristachi R, et al. Electrochemotherapy of cholangiocellular carcinoma at hepatic hilum: a feasibility study. Eur J Surg Oncol 2018; 44: 1603-9. doi: 10.1016/j. ejso.2018.06.025

21. Cindrič H, Kos B, Tedesco G, Cadossi M, Gasbarrini A, Miklavčič D. Electrochemotherapy of spinal metastases using transpedicular approach - a numerical feasibility study. Technol Cancer Res Treat 2018; 17: 1533034618770253. doi: 10.1177/1533034618770253

22. Tarantino L, Busto G, Nasto A, Fristachi R, Cacace L, Talamo M, et al. Percutaneous electrochemotherapy in the treatment of portal vein tumor thrombosis at hepatic hilum in patients with hepatocellular carcinoma in cirrhosis: a feasibility study. World J Gastroenterol 2017; 23: 906-18. doi: 10.3748/wjg.v23.i5.906

23. Cornelis FH, Cindrič $\mathrm{H}$, Kos B, Fujimori M, Petre EN, Miklavčič D, et al. Peritumoral metallic implants reduce the efficacy of irreversible electroporation for the ablation of colorectal liver metastases. Cardiovasc Intervent Radio 2020; 43: 84-93. doi: 10.1007/s00270-019-02300-y
24. Mali B, Gorjup V, Edhemovic I, Brecelj E, Cemazar M, Sersa G, et al. Electrochemotherapy of colorectal liver metastases - an observational study of its effects on the electrocardiogram. Biomed Eng Online 2015; 14 Suppl 3 : S5. doi: 10.1186/1475-925X-14-S3-S5

25. Lu DS, Raman SS, Limanond P, Aziz D, Economou J, Busuttil R, et al. Influence of large peritumoral vessels on outcome of radiofrequency ablation of liver tumors. J Vasc Interv Radio/ 2003; 14: 1267-74. doi: 10.1097/01. rvi.0000092666.72261.6b

26. Baker EH, Thompson K, McKillop IH, Cochran A, Kirks R, Vrochides D, et al. Operative microwave ablation for hepatocellular carcinoma: a single center retrospective review of 219 patients. J Gastrointest Oncol 2017; 8: 337-46. doi: 10.21037/jgo.2016.09.06

27. Baker EH, Thompson K, McKillop IH, Cochran A, Kirks R, Vrochides D, et al. Operative microwave ablation for hepatocellular carcinoma: a single center retrospective review of 219 patients. J Gastrointest Oncol 2017; 8: 337-46. doi: 10.21037/jgo.2016.09.06

28. Wang T, Lu XJ, Chi JC, Ding M, Zhang Y, Tang XY, et al. Microwave ablation of hepatocellular carcinoma as first-line treatment: long term outcomes and prognostic factors in 221 patients. Sci Rep 2016; 6: 32728. doi: 10.1038/ srep32728

29. Ding J, Jing X, Liu J, Wang Y, Wang F, Wang Y, et al. Complications of therma ablation of hepatic tumours: comparison of radiofrequency and microwave ablative techniques. Clin Radiol 2013; 68: 608-15. doi: 10.1016/j. crad.2012.12.008

30. Lucchina N, Tsetis D, lerardi AM, Giorlando F, Macchi E, Kehagias E, et al. Current role of microwave ablation in the treatment of small hepatocellular carcinomas. Ann Gastroenterol 2016; 29: 460-5. doi: 10.20524/ aog.2016.0066

31. Ding J, Jing $X$, Liu J, Wang $Y$, Wang $F$, Wang $Y$, et al. Comparison of two different thermal techniques for the treatment of hepatocellular carcinoma. Eur J Radiol 2013; 82: 1379-84. doi: 10.1016/j.ejrad.2013.04.025

32. Distelmaier $M$, Barabasch $A$, Heil $P$, Kraemer NA, Isfort $P$, Keil $S$, et al. Midterm safety and efficacy of irreversible electroporation of malignant liver tumors located close to major portal or hepatic veins. Radiology 2017; 285: 1023-31. doi: 10.1148/radiol.2017161561

33. Pompili M, Francica G. Irreversible electroporation for hepatic tumors. Ultrasound 2019; 22: 1-3. doi: 10.1007/s40477-019-00367-4

34. Mafeld S, Wong JJ, Kibriya N, Stenberg B, Manas D, Bassett P, et al. Percutaneous irreversible electroporation (IRE) of hepatic malignancy: a bi-institutional analysis of safety and outcomes. Cardiovasc Intervent Radio 2019; 42: 577-83. doi: 10.1007/s00270-018-2120-z

35. Mali B, Jarm T, Corovic S, Paulin-Kosir MS, Cemazar M, Sersa G, et al. The effect of electroporation pulses on functioning of the heart. Med Biol Eng Comput 2008; 46: 745-57. https://doi.org/10.1007/s11517-008-0346-7

36. Ball C, Thomson KR, Kavnoudias H. Irreversible electroporation: a new challenge in "out of operation theatre" anaesthesia. Anesth Analg 2010; 110: 1305-9. doi: 10.1213/ANE.0b013e3181d27b30

37. Mekid $\mathrm{H}$, Tounekti $\mathrm{O}$, Spatz A, Cemazar M, Kebir E, Mir LM. In vivo evolution of tumour cells after the generation of double-strand DNA breaks. $\mathrm{Br} J$ Cancer 2003; 88: 1763-71. doi: 10.1038/sj.bjc.6600959

38. Markelc B, Sersa G, Cemazar M. Differential mechanisms associated with vascular disrupting action of electrochemotherapy: intravital microscopy on the level of single normal and tumor blood vessels. PLoS One 2013; 8: e59557. doi: 10.1371/journal.pone.0059557

39. Calvet CY, Famin D, André FM, Mir LM. Electrochemotherapy with bleomycin induces hallmarks of immunogenic cell death in murine colon cancer cells. Oncoimmunology 2014; 3: e28131. doi: 10.4161/onci.28131

40. Sersa G, Teissie J, Cemazar M, Signori E, Kamensek U, Marshall G et al. Electrochemotherapy of tumors as in situ vaccination boosted by immunogene electrotransfer. Cancer Immunol Immunother 2015; 64: 1315-27. doi: 10.1007/s00262-015-1724-2

41. Heppt MV, Eigentler TK, Kähler KC, Herbst RA, Göppner D, Gambichler T, et al. Immune checkpoint blockade with concurrent electrochemotherapy in advanced melanoma: a retrospective multicenter analysis. Cancer Immunol Immunother 2016; 65: 951-9. doi: 10.1007/s00262-016-1856-z 